\title{
Study of association of PAX6 polymorphisms with susceptibility to high myopia in a Japanese population
}

This article was published in the following Dove Press journal:

Clinical Ophthalmology

27 October 2015

Number of times this article has been viewed

\author{
Nobuyuki Kanemaki' \\ Akira Meguro 2 \\ Takahiro Yamane ${ }^{2}$ \\ Masaki Takeuchi ${ }^{2,3}$ \\ Eiichi Okada ${ }^{4}$ \\ Yasuhito lijima ${ }^{5}$ \\ Nobuhisa Mizuki² \\ 'Veterinary Teaching Hospital, Azabu \\ University, Sagamihara, ${ }^{2}$ Department \\ of Ophthalmology and Visual Science, \\ Yokohama City University Graduate \\ School of Medicine, Yokohama, \\ Kanagawa, Japan; ${ }^{3}$ Inflammatory \\ Disease Section, National Human \\ Genome Research Institute, National \\ Institutes of Health, Bethesda, MD, \\ USA; ${ }^{4}$ Okada Eye Clinic, ${ }^{5}$ Aoto Eye \\ Clinic, Yokohama, Kanagawa, Japan
}

Correspondence: Akira Meguro Department of Ophthalmology and Visual Science, Yokohama City University Graduate School of Medicine, 3-9 Fukuura, Kanazawa-ku, Yokohama, Kanagawa 236-0004, Japan

Tel +8I 457872683

Fax +8I 45 78। 9755

Email akmeguro@yokohama-cu.ac.jp
Purpose: Many studies have investigated the relationship of paired box 6 (PAX polymorphisms with the risk of high myopia, but the results across studies remain inconsistent and ambiguous. In the present work, we investigated whether $P A X 6$ polymorphisms are associated with high myopia in a Japanese population.

Methods: A total of 1,585 Japanese patients with high myopia (spherical equivalent [SE] $<-9.00$ diopters $[\mathrm{D}])$ and 1,011 Japanese healthy controls ( $\mathrm{SE} \geq-1.00 \mathrm{D})$ were recruited. To compare genotype frequencies between cases and controls, we genotyped five single nucleotide polymorphisms in the PAX6 gene that are reportedly associated with high/extreme myopia: rs662702, rs3026393, rs644242, rs3026390, and rs667773.

Results: For rs662702, rs644242, and rs667773, odds ratios (ORs) for their risk alleles tended to increase with the progression of SE and axial length in the additive and recessive models. Of these, rs644242 had the highest OR (2.56) in patients with $\mathrm{SE}<-15 \mathrm{D}$ in both eyes in the recessive model. On the other hand, for rs3026393 and rs3026390, the ORs for their risk alleles tended to increase according to the progression of SE and axial length in the dominant model. Of the two, rs3026393 had the highest OR (2.32) in patients with $\mathrm{SE}<-15 \mathrm{D}$ in both eyes in the dominant model. However, no significant associations were identified in this study.

Conclusion: We found that these $P A X 6$ single nucleotide polymorphisms were associated with an increased risk of extreme myopia. Although the results, which are in agreement with some previous studies, did not reach statistical significance, $P A X 6$ single nucleotide polymorphisms may be important risk factors for the development of extreme myopia. Further genetic studies with larger sample sizes and taking into account the degree of myopia are needed to clarify the contribution of $P A X 6$ variants in myopia development.

Keywords: high myopia, $P A X 6$, association study, polymorphism

\section{Introduction}

Myopia is a refractive visual disorder that is considered an important public health problem, especially in Asian populations. High myopia is generally defined by a spherical equivalent (SE) refractive error $<-6$ diopters (D) or an axial length (AL) $>26 \mathrm{~mm}$ that can cause blindness associated with an increased risk of various ocular diseases, including retinal detachment, glaucoma, cataracts, and macular degeneration. ${ }^{1}$ Because of its high prevalence compared to the global average in Asian countries such as the People's Republic of China, Singapore, and Japan, high myopia imposes enormous economic and social burdens in these regions..$^{2-5}$

Although the cause of myopia is unclear, family-based studies and twin studies have shown that genetic factors contribute to its development and progression. ${ }^{6-13}$ Therefore, the identification of genetic factors is important for establishing preventive 
strategies for myopia. To date, 18 genetic loci for myopia (MYP1 to MYP18) have been reported by familial linkage studies. ${ }^{14}$ In the past several years, genome-wide association studies have led to the identification of many important genetic loci/genes involved in myopia, refractive error, and elongation of AL. ${ }^{15-18}$ Recently, environmental factors such as education have been reported to influence the association between genetic factors and myopia. ${ }^{19-21}$

The paired box 6 ( $P A X 6)$ gene, located on chromosome $11 \mathrm{p} 13$, is a highly conserved family of transcription factors containing the paired and homeobox DNA-binding domains. PAX6 regulates the expression of various molecules, such as cell adhesion molecules, cell-cell signaling molecules, hormones, and structural eye proteins, and the gene plays a critical role in the development of the central nervous system and the eye. ${ }^{22}$ Mutations in the $P A X 6$ gene result in various ocular diseases including aniridia, foveal hypoplasia, presenile cataract, and aniridia-related keratopathy. ${ }^{23}$ In 2004, a genome-wide linkage analysis in UK dizygotic twins showed the highest peak at the $11 \mathrm{p} 13$ locus and strong linkage for refractive error in the vicinity of $P A X 6$ at this locus. ${ }^{24}$ Subsequently, the results of some genetic surveys suggested an association of single nucleotide polymorphisms (SNPs) in $P A X 6$ with high and/or extreme myopia in Taiwanese, Chinese, and Japanese populations, ${ }^{25-28}$ suggesting that $P A X 6$ may contribute to the development of high/extreme myopia through genetic polymorphisms. However, other studies have reported a lack of association of $P A X 6$ SNPs with refractive error, myopia, or high myopia in British, Chinese, and mixed populations of some ethnic groups (including mainly Caucasians). ${ }^{29-32}$

Further genetic studies thus are needed to clarify the contribution of the $P A X 6$ region to myopia development. The aim of the current study was to investigate whether SNPs in the $P A X 6$ region are associated with high/extreme myopia in our Japanese population.

\section{Methods}

\section{Subjects}

We recruited 1,585 unrelated Japanese patients with high myopia ( $\mathrm{SE}<-9.00 \mathrm{D}$ in at least one eye) and 1,011 unrelated healthy Japanese controls ( $\mathrm{SE} \geq-1.00 \mathrm{D}$ in both eyes) at Yokohama City University, Okada Eye Clinic, and Aoto Eye Clinic in Japan. Participants were unrelated to each other, had similar social backgrounds, and resided in the same urban area. All participants were diagnosed by comprehensive ophthalmologic tests, including AL, fundus examination, spherical power, and corneal curvature (autorefractor; NIDEK [Gamagori, Japan]; ARK-730A, ARK-700A, TOPCON [Tokyo, Japan]; KP-8100P, Biometer/Pachymeter AL-2000;
Tomey Corporation, Nagoya, Japan). Those with high myopia had no known genetic diseases associated with myopia and/or high myopia, including glaucoma, keratoconus, and Marfan syndrome. We excluded individuals younger than 20 years, which may include potential myopia patients, from the control cohort. Informed consent was obtained from all participants. The study methodology adhered to the tenets of the Declaration of Helsinki and was approved by the relevant ethics committees in Yokohama City University, Okada Eye Clinic, and Aoto Eye Clinic.

\section{DNA and PAX6 genotyping}

The QIAamp DNA Blood Maxi Kit (Qiagen, Hilden, Germany) was used to collect peripheral blood lymphocytes and extract genomic DNA from peripheral blood cells. Procedures were performed under standardized conditions to prevent variation in DNA quality.

We evaluated five SNPs in the PAX6 gene regions: rs662702, rs3026393, rs644242, rs3026390, and rs667773. All five have previously been reported to be associated with high or extreme myopia. ${ }^{25-28}$ Genotyping of all SNPs was performed using the TaqMan $5^{\prime}$ exonuclease assay with primer-probe sets supplied by Applied Biosystems (Foster City, CA, USA). Polymerase chain reaction (PCR) was performed using a reaction mixture with a total volume of $10 \mu \mathrm{L}$ containing $1 \times$ TaqMan Universal PCR Master Mix (Applied Biosystems), $24 \mathrm{nM}$ of each primer-probe set, and 3 ng genomic DNA. The PCR conditions were as follows: $95^{\circ} \mathrm{C}$ for 10 minutes, followed by 40 cycles of denaturation at $92^{\circ} \mathrm{C}$ for 15 seconds and annealing/extension at $60^{\circ} \mathrm{C}$ for 1 minute. The probe fluorescence signal was detected using the StepOnePlus Real-Time PCR System (Applied Biosystems) following the manufacturer's instructions.

\section{Statistical analysis}

Genetic data were analyzed using SNP and Variation Suite v8 (Golden Helix, Inc., Bozeman, MT, USA, http://www. goldenhelix.com). Multiple inheritance models were applied in analysis of genotype data to assess each risk allele; additive ( $\mathrm{R} / \mathrm{R}$ vs $\mathrm{R} / \mathrm{nR}$ vs $\mathrm{nR} / \mathrm{nR}$ ), dominant ( $\mathrm{R} / \mathrm{R}+\mathrm{R} / \mathrm{nR}$ vs $\mathrm{nR} / \mathrm{nR})$, and recessive ( $\mathrm{R} / \mathrm{R}$ vs $\mathrm{R} / \mathrm{nR}+\mathrm{nR} / \mathrm{nR}$ ) models (assuming that $\mathrm{R}$ is the risk allele and $\mathrm{nR}$ is the non-risk allele) were assessed. All $P$-values and odds ratios (ORs) were adjusted for age and sex. Linkage disequilibrium (LD) was assessed using Haploview 4.1 (Broad Institute, Cambridge, MA, USA). ${ }^{33}$

\section{Results}

The clinical characteristics of the study populations are shown in Table 1. Patient age ranged from 12 to 78 years 
Table I Clinical characteristics of the study populations

\begin{tabular}{|c|c|c|}
\hline Parameters & $\begin{array}{l}\text { High myopia }^{b} \\
(n=1,585)\end{array}$ & $\begin{array}{l}\text { Controls } \\
(n=I, 0 I I)\end{array}$ \\
\hline Male, \% & 44.2 & 41.6 \\
\hline Mean age, ${ }^{a}$ (years) & $38.8 \pm 12.2$ & $58.2 \pm 12.3$ \\
\hline Age range & $(12,78)$ & $(20,87)$ \\
\hline \multicolumn{3}{|c|}{ Mean SE, diopter (D) } \\
\hline Right eyes & $-10.94 \pm 2.06$ & $0.48 \pm 0.64$ \\
\hline Left eyes & $-10.82 \pm 2.07$ & $0.48 \pm 0.63$ \\
\hline \multicolumn{3}{|l|}{ Range of SE } \\
\hline Right eyes & $(-4.50,-22.75)$ & $(-1.00,3.50)$ \\
\hline Left eyes & $(-4.50,-24.50)$ & $(-1.00,3.00)$ \\
\hline \multicolumn{3}{|l|}{ Mean AL, ${ }^{\mathrm{a}} \mathrm{mm}$} \\
\hline Right eyes & $27.55 \pm 1.22$ & $23.22 \pm 0.80$ \\
\hline Left eyes & $27.5 I \pm I .24$ & $23.20 \pm 0.79$ \\
\hline \multicolumn{3}{|l|}{ Range of $A L$} \\
\hline Right eyes & $(23.92,33.85)$ & $(18.76,25.96)$ \\
\hline Left eyes & $(23.99,34.74)$ & $(18.99,26.05)$ \\
\hline
\end{tabular}

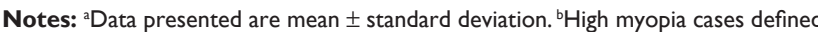
as $S E<-9.0 \mathrm{D}$ in at least one eye. 'Controls defined as $S E \geq-1.0 \mathrm{D}$ in both eyes. Abbreviations: AL, axial length; SE, spherical equivalent.

(mean $38.8 \pm 12.2$ years), and $44.2 \%$ of patients were male. The average SEs were $-10.94 \pm 2.06 \mathrm{D}$ (range -4.50 to $-22.75 \mathrm{D})$ in the right eye and $-10.82 \pm 2.07 \mathrm{D}$ (range -4.50 to $-24.50 \mathrm{D}$ ) in the left eye. The average AL was $27.55 \pm 1.22 \mathrm{~mm}$ (range $23.92-33.85 \mathrm{~mm}$ ) for the right eye and $27.51 \pm 1.24 \mathrm{~mm}$ (range 23.99-34.74 mm) for the left eye. For the controls, the age ranged from 20 to 87 years (mean $58.2 \pm 12.3$ years), and $41.6 \%$ of them were male. The average SEs were $0.48 \pm 0.64 \mathrm{D}$ (range -1.00 to $3.50 \mathrm{D}$ ) in the right eye and $0.48 \pm 0.63 \mathrm{D}$ (range -1.00 to $3.00 \mathrm{D}$ ) in the left eye. Average $\mathrm{AL}$ values were $23.22 \pm 0.80 \mathrm{~mm}$ (range 18.76-25.96 mm) and $23.20 \pm 0.79 \mathrm{~mm}$ (range 18.99-26.05 $\mathrm{mm}$ ) for the right and left eyes, respectively.

The genotype frequencies of all five SNPs in $P A X 6$ were in Hardy-Weinberg equilibrium in controls $(P>0.05)$. The magnitude of LD among three SNPs (rs662702, rs644242, and rs667773) was extremely high $\left(r^{2} \geq 0.98\right)$ while the remaining two SNPs (rs3026393 and rs3026390) were in complete LD $\left(r^{2}=1.00\right)$. These two LD blocks were not linked to each other $\left(r^{2} \leq 0.10\right)$.

Table 2 shows genotypic association results for the SNPs after stratification according to SE in high myopia cases; that is, $<-9.0 \mathrm{D}$ in at least one eye, $<-9.0 \mathrm{D}$ in both eyes, $<-11.0 \mathrm{D}$ in both eyes, $<-13.0 \mathrm{D}$ in both eyes, and $<-15.0 \mathrm{D}$ in both eyes. For rs662702, rs644242, and rs667773, ORs for their risk alleles tended to increase according to the progression of $\mathrm{SE}$ in the additive and recessive models, and marginal associations were found in patients with $\mathrm{SE}<-15.0 \mathrm{D}$ in both eyes for rs644242 and rs667773 (rs644242: $P=0.069$ and $\mathrm{OR}=2.51$; rs667773:
$P=0.071$ and $\mathrm{OR}=2.50$ for the additive model; rs644242: $P=0.093$ and $\mathrm{OR}=2.56$; rs667773: $P=0.095$ and $\mathrm{OR}=2.55$ for the recessive model).On the other hand, for rs3026393 and rs3026390, ORs for their risk alleles tended to increase with the progression of SE in the dominant model, and marginal associations were found in patients with $\mathrm{SE}<-15.0 \mathrm{D}$ in both eyes (rs3026393: $P=0.068$ and $\mathrm{OR}=2.32$; rs3026390: $P=0.075$ and $\mathrm{OR}=2.28)$.

Table 3 shows genotypic association results after stratification according to AL in high myopia cases, as follows: $>26,>28,>29$, and $>30 \mathrm{~mm}$ in both eyes. For rs662702, rs644242, and rs667773, ORs for their risk alleles tended to increase according to the progression of $\mathrm{AL}$ in the additive and recessive models, and the highest ORs were observed in patients with $\mathrm{AL}>30 \mathrm{~mm}$ in both eyes in the recessive model $(\mathrm{OR}=1.87-1.90)$. On the other hand, for rs3026393 and rs3026390, ORs for their risk alleles tended to increase according to the progression of AL in the dominant model, and the highest ORs were observed in patients with $\mathrm{AL}>30 \mathrm{~mm}$ in both eyes ( $\mathrm{OR}=1.79$ and 1.78 , respectively). However, no significant associations were found in this genotypic analysis.

\section{Discussion}

The aim of the present study was to assess whether polymorphisms in the PAX6 gene region affect the development of high/extreme myopia in our Japanese population. Patients with $\mathrm{SE}<-9.00 \mathrm{D}$ in at least one eye were selected for this study because higher degree of myopia suggests that genetic factors may show stronger involvement. We genotyped five polymorphisms in the region and found that the relationship between $P A X 6$ SNPs and myopia became stronger with the progression of myopia, although it did not reach statistical significance. Our findings suggest that $P A X 6$ SNPs play an important role in the risk of extreme myopia in the Japanese population.

Tsai et $\mathrm{al}^{25}$ found a significantly higher frequency of the CC genotype of rs667773 in extreme myopia ( $\mathrm{SE}<-10.0 \mathrm{D}$ in both eyes) $(\mathrm{OR}=5.265)$ but not high myopia $(\mathrm{SE}<-6.0 \mathrm{D}$ in both eyes) compared to controls in Chinese Taiwanese. Liang et $\mathrm{al}^{27}$ reported that the frequencies of the GG genotype of rs662702 and rs644242, which are in extremely high LD with rs667773, significantly increased with the progression of myopia in Chinese Taiwanese and that the GG genotypes of rs662702 and rs644242 had the highest ORs (2.1 and 2.3 , respectively) in extreme myopia ( $\mathrm{SE} \leq-11.0 \mathrm{D}$ in both eyes). Additionally, Miyake et $\mathrm{al}^{28}$ reported that rs644242 showed a significant association with high (AL $\geq 26 \mathrm{~mm}$ in both eyes) and extreme ( $\mathrm{AL} \geq 28 \mathrm{~mm}$ in both eyes) myopia in a Japanese population and that the $\mathrm{G}$ allele was protective 


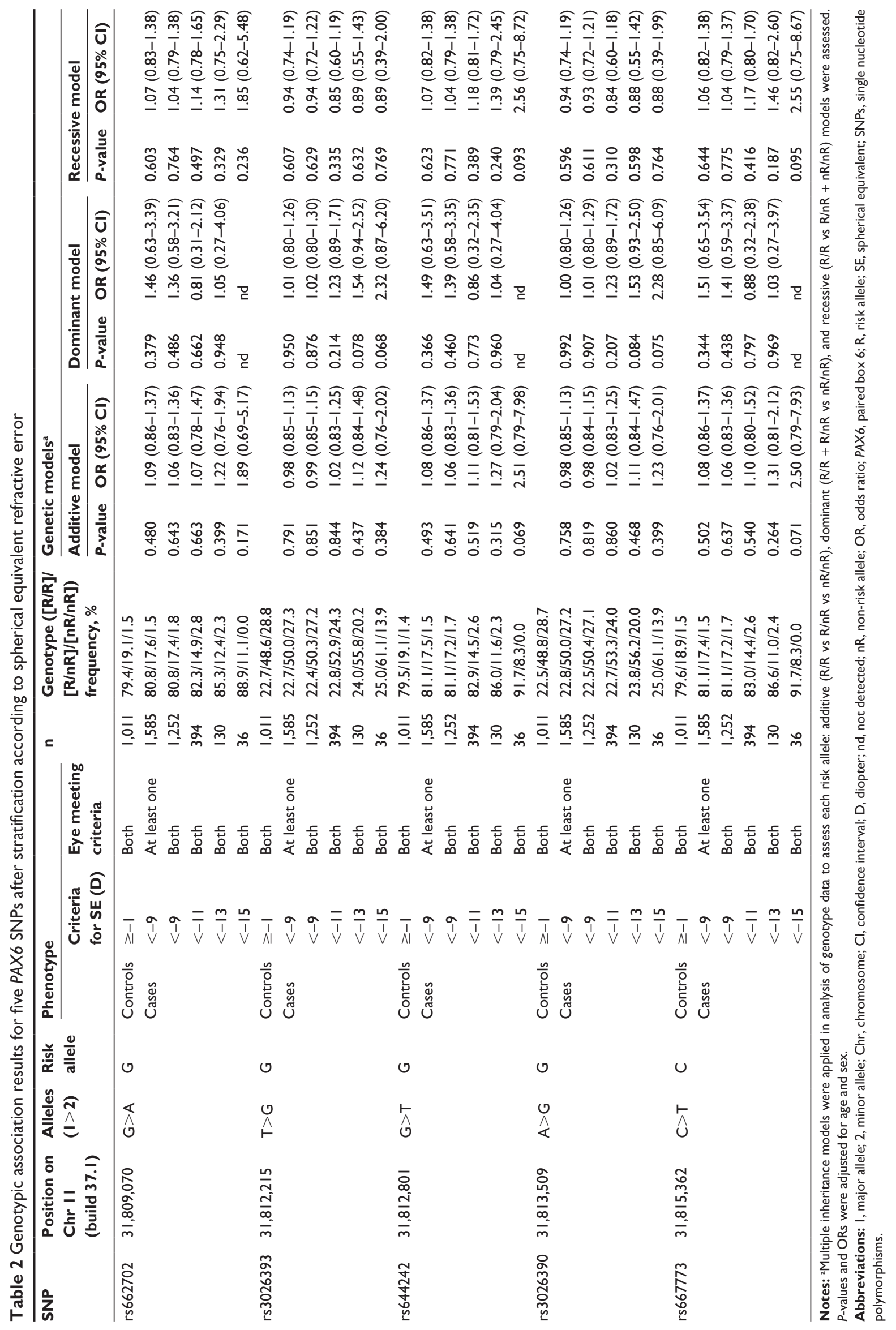




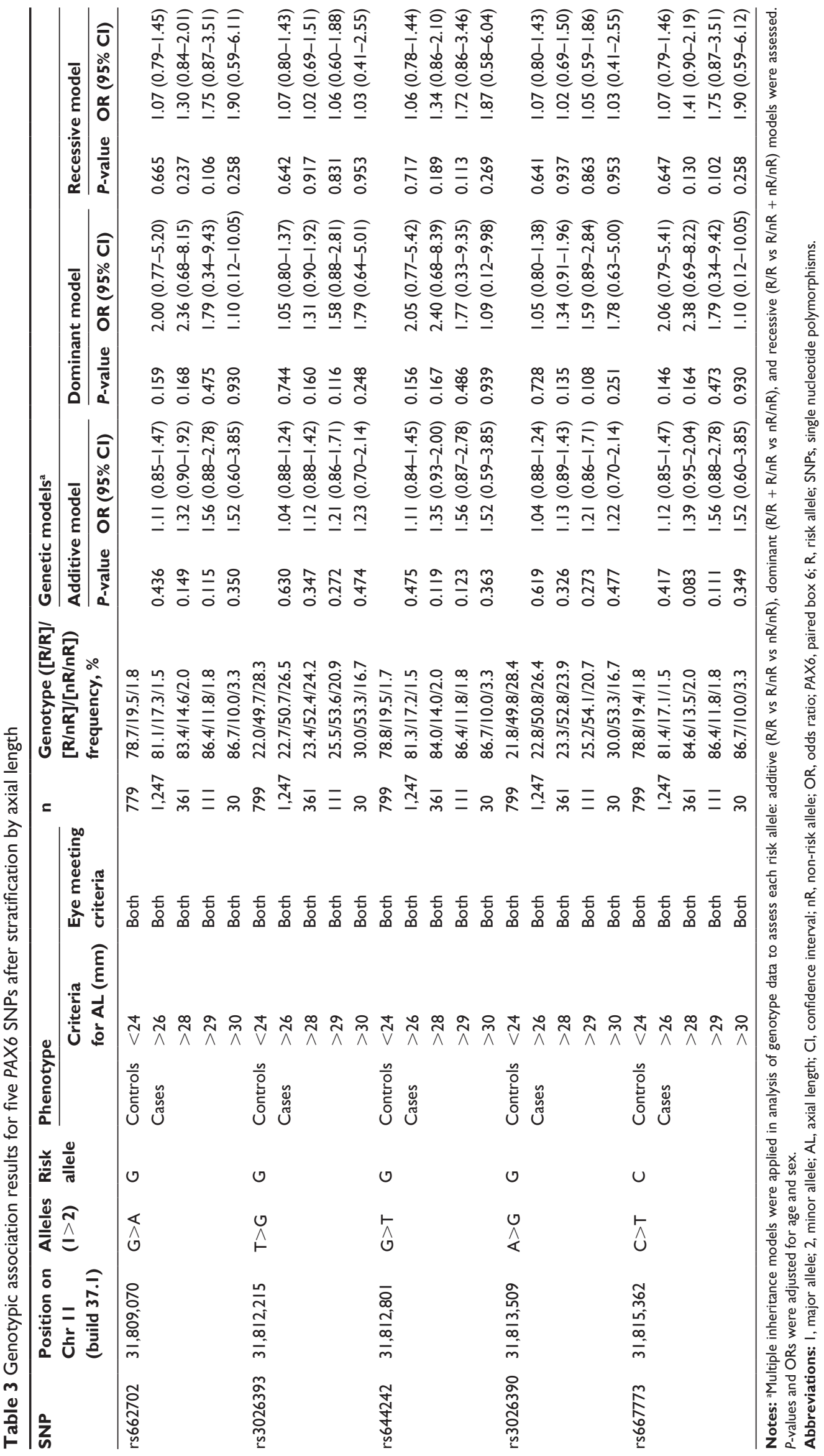


for both. In the present study, in a Japanese population, we found that the $\mathrm{CC}$ genotype of rs667773 and the GG genotype of rs644242 (recessive model) had the highest ORs (2.55 and 2.56 , respectively) in extreme myopia with $\mathrm{SE}<-15.0 \mathrm{D}$ in both eyes and that the GG genotype of rs662702 (recessive model) had the highest OR (1.90) in extreme myopia with $\mathrm{AL} \geq 30 \mathrm{~mm}$ in both eyes. These findings are in line with the previous studies. Considering the above, the risk allele(s) of rs667773, rs644242, and/or rs662702 may contribute to the development of extreme myopia under the recessive model.

On the other hand, other studies have not found a relationship between rs667773/rs662702 and myopia in several populations. ${ }^{26,29-32}$ However, these authors, with the exception of Dai et al, ${ }^{32}$ did not perform an analysis targeting extreme myopia, and moreover, almost all of them, including Dai et al, ${ }^{32}$ used limited sample sizes, with the potential to yield false results. ${ }^{26,29-32}$ Therefore, it is assumed that these previous studies had not been performed under appropriate conditions to assess associations between rs667773/rs644242/rs662702 and extreme myopia.

Han et $\mathrm{al}^{26}$ demonstrated that the T allele of rs3026393 and the A allele of rs3026390 are associated with a significantly increased risk of high myopia $(<-6.0 \mathrm{D})$ in dominant and recessive models in Han Chinese. In the present study, we found that the ORs of the G allele of rs3026393 and the $\mathrm{G}$ allele of rs3026390 increased according to the progression of myopia in the dominant model. Our result diverges from that of Han et al, ${ }^{26}$ in that the disease risk-related allele differs between the present and previous studies for rs3026393 and rs3026390. Moreover, other studies found no relationship between the genotypes and myopia in Han Chinese, Chinese Taiwanese, and British populations. ${ }^{27,29,31,32}$ None of these previous studies ${ }^{26,27,29,31,32}$ involved analyses targeting extreme myopia with $\mathrm{SE}<-13.0 \mathrm{D}$ or $<-15.0 \mathrm{D}$, which had higher ORs (OR > 1.50) at rs3026393 and rs3026390 in the present study (the study by Han et $\mathrm{al}^{26}$ used the lowest SE cutoff point $[\leq-10.0 \mathrm{D}]$ among the previous studies). Because the present study found that ORs for rs3026393 and rs3026390 were proportionate to the progression of myopia in the dominant model and that lower ORs $(\leq 1.23)$ were observed in myopia patients with $\mathrm{SE}<-11.0 \mathrm{D}$, there is a possibility that these earlier studies ${ }^{26,27,29,31,32}$ failed to detect the association between rs3026393/rs3026390 and extreme myopia.

In conclusion, we found that all of the PAX6 SNPs tested in this study were associated with an increased risk of extreme myopia. However, the results did not reach statistical significance; this is probably due to small sample sizes after stratification by SE or AL. Further genetic studies with larger sample sizes and consideration of degree of myopia are needed to elucidate the possible contributions of the PAX6 region in myopia development.

\section{Acknowledgments}

This study was supported by JSPS KAKENHI grant number 23590382. We thank all the participants for their participation in this study and all the medical staff involved in sample collection and diagnosis.

\section{Disclosure}

The authors report no conflicts of interest in this work.

\section{References}

1. Saw SM, Gazzard G, Shih-Yen EC, Chua WH. Myopia and associated pathological complications. Ophthalmic Physiol Opt. 2005;25(5): 381-391.

2. He M, Zeng J, Liu Y, Xu J, Pokharel GP, Ellwein LB. Refractive error and visual impairment in urban children in Southern China. Invest Ophthalmol Vis Sci. 2004;45(3):793-799.

3. Qian YS, Chu RY, He JC, et al. Incidence of myopia in high school students with and without red-green color vision deficiency. Invest Ophthalmol Vis Sci. 2009;50(4):1598-1605.

4. Seet B, Wong TY, Tan DT, et al. Myopia in Singapore: taking a public health approach. Br J Ophthalmol. 2001;85(5):521-526.

5. Matsumura H, Hirai H. Prevalence of myopia and refractive changes in students from 3 to 17 years of age. Surv Ophthalmol. 1999;44:S109-S115.

6. Wu MM, Edwards MH. The effect of having myopic parents: an analysis of myopia in three generations. Optom Vis Sci. 1999;76(6):387-392.

7. Guggenheim JA, Kirov G, Hodson SA. The heritability of high myopia: a reanalysis of Goldschmidt's data. J Med Genet. 2000;37(3): 227-231.

8. Mutti DO, Mitchell GL, Moeschberger ML, Jones LA, Zadnik K. Parental myopia, near work, school achievement, and children's refractive error. Invest Ophthalmol Vis Sci. 2002;43(12):3633-3640.

9. Farbrother JE, Kirov G, Owen MJ, Guggenheim JA. Family aggregation of high myopia: estimation of the sibling recurrence risk ratio. Invest Ophthalmol Vis Sci. 2004;45(9):2873-2878.

10. Liang CL, Yen E, Su JY, et al. Impact of family history of high myopia on level and onset of myopia. Invest Ophthalmol Vis Sci. 2004;45(10): 3446-3452.

11. Klein AP, Duggal P, Lee KE, Klein R, Bailey-Wilson JE, Klein BE. Support for polygenic influences on ocular refractive error. Invest Ophthalmol Vis Sci. 2005;46(2):442-446.

12. Sorsby A, Fraser GR. Statistical note on the components of ocular refraction in twins. J Med Genet. 1964;1(1):47-49.

13. Lyhne N, Sjølie AK, Kyvik KO, Green A. The importance of genes and environment for ocular refraction and its determiners: a population based study among 20-45 year old twins. Br J Ophthalmol. 2001;85(12): 1470-1476.

14. Yu L, Li ZK, Gao JR, Liu JR, Xu CT. Epidemiology, genetics and treatments for myopia. Int J Ophthalmol. 2011;4(6):658-669.

15. Hysi PG, Wojciechowski R, Rahi JS, Hammond CJ. Genome-wide association studies of refractive error and myopia, lessons learned, and implications for the future. Invest Ophthalmol Vis Sci. 2014;55(5): 3344-3351.

16. Fan Q, Barathi VA, Cheng CY, et al. Genetic variants on chromosome 1q41 influence ocular axial length and high myopia. PLoS Genet. 2012; 8(6):e1002753.

17. Cheng CY, Schache M, Ikram MK, et al. Nine loci for ocular axial length identified through genome-wide association studies, including shared loci with refractive error. Am J Hum Genet. 2013;93(2):264-277. 
18. Miyake M, Yamashiro K, Tabara Y, et al. Identification of myopiaassociated WNT7B polymorphisms provides insights into the mechanism underlying the development of myopia. Nat Commun. 2015; 6:6689.

19. Fan Q, Wojciechowski R, Kamran Ikram M, et al. Education influences the association between genetic variants and refractive error: a metaanalysis of five Singapore studies. Hum Mol Genet. 2014;23(2): 546-554.

20. Verhoeven VJ, Buitendijk GH, Consortium for Refractive Error and Myopia (CREAM), et al. Education influences the role of genetics in myopia. Eur J Epidemiol. 2013;28(12):973-980.

21. Goldschmidt E, Jacobsen N. Genetic and environmental effects on myopia development and progression. Eye (Lond). 2014;28(2):126-133.

22. Simpson TI, Price DJ. Pax6; a pleiotropic player in development Bioessays. 2002;24(11):1041-1051.

23. Tsonis PA, Fuentes EJ. Focus on molecules: Pax-6, the eye master. Exp Eye Res. 2006;83(2):233-234.

24. Hammond CJ, Andrew T, Mak YT, Spector TD. A susceptibility locus for myopia in the normal population is linked to the PAX6 gene region on chromosome 11: a genomewide scan of dizygotic twins. Am J Hum Genet. 2004;75(2):294-304.

25. Tsai YY, Chiang CC, Lin HJ, Lin JM, Wan L, Tsai FJ. A PAX6 gene polymorphism is associated with genetic predisposition to extreme myopia. Eye (Lond). 2008;22(4):576-581.
26. Han W, Leung KH, Fung WY, et al. Association of PAX6 polymorphisms with high myopia in Han Chinese nuclear families. Invest Ophthalmol Vis Sci. 2009;50(1):47-56.

27. Liang CL, Hsi E, Chen KC, Pan YR, Wang YS, Juo SH. A functional polymorphism at 3'UTR of the PAX6 gene may confer risk for extreme myopia in the Chinese. Invest Ophthalmol Vis Sci. 2011;52(6): 3500-3505.

28. Miyake M, Yamashiro K, Nakanishi H, et al. Association of paired box 6 with high myopia in Japanese. Mol Vis. 2012;18:2726-2735.

29. Simpson CL, Hysi P, Bhattacharya SS, et al. The roles of PAX6 and SOX2 in myopia: lessons from the 1958 British Birth Cohort. Invest Ophthalmol Vis Sci. 2007;48(10):4421-4425.

30. Mutti DO, Cooper ME, O'Brien S, et al. Candidate gene and locus analysis of myopia. Mol Vis. 2007;13:1012-1019.

31. Jiang B, Yap MK, Leung KH, et al. PAX6 haplotypes are associated with high myopia in Han Chinese. PLoS One. 2011;6(5):e19587.

32. Dai L, Li Y, Du CY, et al. Ten SNPs of PAX6, Lumican, and MYOC genes are not associated with high myopia in Han Chinese. Ophthalmic Genet. 2012;33(3):171-178.

33. Barrett JC, Fry B, Maller J, Daly MJ. Haploview: analysis and visualization of LD and haplotype maps. Bioinformatics. 2005;21(2): $263-265$.
Clinical Ophthalmology

\section{Publish your work in this journal}

Clinical Ophthalmology is an international, peer-reviewed journal covering all subspecialties within ophthalmology. Key topics include: Optometry; Visual science; Pharmacology and drug therapy in eye diseases; Basic Sciences; Primary and Secondary eye care; Patient Safety and Quality of Care Improvements. This journal is indexed on

Submit your manuscript here: http://www.dovepress.com/clinical-ophthalmology-journal

\section{Dovepress}

PubMed Central and CAS, and is the official journal of The Society of Clinical Ophthalmology (SCO). The manuscript management system is completely online and includes a very quick and fair peer-review system, which is all easy to use. Visit http://www.dovepress.com/ testimonials.php to read real quotes from published authors. 